\title{
PRODUÇÃO DE PLANTAS Malpighia punicifolia L. EM DIFERENTES SUBSTRATOS
}

Juliana Teodora de Assis Reges ${ }^{1}$, Nádia Maria Poloni ${ }^{2}$, João Alberto Fischer Filho ${ }^{3}$, Izabela Lopes Garcia ${ }^{4}$, Matheus Mereb Negrisoli ${ }^{4}$, Luiz de Souza Corrêa ${ }^{5}$

\footnotetext{
${ }^{1}$ Doutora em Agronomia - Universidade Estadual Paulista (UNESP), Faculdade de Engenharia, Ilha Solteira SP; e Docente da Universidade Estadual de Goiás - Campus de Jataí (GO). Autor Para Correspondência: juliana.teodora@bol.com.br.

${ }^{2}$ Mestranda em Agronomia na Universidade Estadual Paulista (UNESP), Faculdade de Engenharia, Ilha Solteira $-\mathrm{SP}$.

${ }^{3}$ Doutorando em Agronomia na Universidade Estadual Paulista (UNESP), Faculdade de Ciências Agrárias e Veterinárias, Jaboticabal

${ }^{4}$ Graduando(a) em Agronomia na Universidade Estadual Paulista (UNESP), Faculdade de Engenharia, Ilha Solteira - SP

${ }^{5}$ Prof. Adjunto do Departamento de Fitossanidade, Engenharia Rural e Solos da Universidade Estadual Paulista (UNESP), Faculdade de Engenharia, Ilha Solteira - SP
}

RESUMO: Este trabalho teve como objetivo avaliar a calagem, o cultivo orgânico e mineral, na fase de formação de mudas de acerola em viveiro, também observar as correlações fenotípicas, genotípicas e ambientais entre atributos quantitativos da aceroleira. O experimento foi realizado no viveiro da Fazenda de Ensino Pesquisa e Extensão da UNESP Campus de Ilha Solteira. Três cultivares foram analisadas em delineamento experimental de blocos ao acaso, com quatro repetições, em oito tratamentos (adubação mineral, orgânica, calcário e micronutrientes) com 11 mudas úteis por parcela no viveiro. Foram avaliados a porcentagem de germinação, comprimento da parte aérea, comprimento radicular, número de folhas, massa da matéria seca da parte aérea e das raízes das mudas de aceroleira aos 9 meses de idade. A adição de esterco bovino propiciou mudas com maior qualidade, especialmente acompanhada de adubação mineral; os substratos da mistura de superfosfato simples (SFS) + FTE-BR12 + esterco bovino + calcário) e de SFS + FTE-BR12 + esterco bovino propiciaram maior desenvolvimento das mudas. Há correlações genotípicas e fenotípicas positivas diretamente proporcionais entre porcentagem de germinação e número de folhas, massa seca da parte aérea e massa seca da raiz.

Palavras-chave: Acerola. Genotípica. Adubação orgânica. Adubação mineral.

\section{PRODUCTION OF PLANTS Malpighia punicifolia L. IN DIFFERENT SUBSTRATES}

\begin{abstract}
This study aimed to evaluate liming, organic and mineral cultivation, at the stage of acerola seedling in nurseries, also to observe the phenotypic, genotypic and environmental correlations between quantitative attributes of acerola. The experiment was conducted in the nursery of "Fazenda de Ensino Pesquisa e Extensão of UNESP - Campus of
\end{abstract}

Cultura Agronômica, Ilha Solteira, v.25, n.4, p.419-430, 2016 
Ilha Solteira". Three cultivars were analyzed in experimental design of randomized blocks with four replications in eight treatments (mineral fertilizer, organic, lime and micronutrients) with 11 seedlings per plot in the nursery. It was evaluated the percentage of germination, shoot length, root length, number of leaves, dry matter of shoot and root of acerola seedlings at 9-month-old. The addition of manure led seedlings with higher quality, especially accompanied by mineral fertilizer; the substrates of the mixture of superphosphate (SFS) + FTE-BR12 + manure + limestone) and the SFS + FTE-BR12 + manure provided higher seedling development. There are positive genotypic and phenotypic correlations directly proportional to germination percentage, number of leaves, and dry weight of shoot and root mass.

Key words: Acerola. Genotypic. Organic fertilizer. Mineral fertilizer.

\section{INTRODUÇÃO}

A acerola (Malpighia punicifolia L.), também conhecida como cereja-das-antilhas, é uma fruta originária da região do mar do Caribe. A espécie é considerada uma das maiores fontes naturais de vitamina $\mathrm{C}$, superando em várias vezes frutas como goiaba, caju, laranja e limão, que são excelentes fontes dessa vitamina (ALVES et al., 1995). A qualidade de frutos da acerola é relacionada aos valores nutricionais do solo, a aparência externa e a composição da polpa (PEDÓ et al., 2014).

A forma usual para a produção de mudas de aceroleira, geralmente, consiste no uso de misturas empíricas de materiais no substrato, cujas características físico-químicas, em sua maioria, são desconhecidas (LIMA et al., 2005). Apesar da instalação de grande quantidade de novos pomares de aceroleira, em áreas de baixa fertilidade, a literatura sobre a nutrição e adubação ainda é escassa. Dessa maneira, ao se discutir esse assunto deve-se ter bastante cautela, mesmo por que não se pode recomendar adubação com segurança, baseando-se em outras culturas (CRISÓSTOMO; NAUMOV, 2009).

Para a obtenção de mudas de boa qualidade, tanto no aspecto nutricional como fitossanitário, é necessário dispor de materiais para uso como substrato com características físicas e químicas apropriadas, além da facilidade de aquisição nas proximidades do local de produção e baixos custos para a obtenção (FARIAS et al., 2012; LIMA et al., 2005). Portanto, é possível que misturas de substratos possam favorecer o maior desenvolvimento das mudas no campo, diminuindo, assim, os custos de produção. Materiais tais como esterco bovino, superfosfato simples, calcário, fontes de micronutrientes, dentre outros, tem se destacado para compor substratos para a produção de mudas. A qualidade do substrato resulta da combinação de suas propriedades químicas e físicas, as quais podem ser ajustadas pela formulação de misturas duplas ou triplas (CARDONA et al., 2016; NEGREIROS et al., 2004).

Nesse contexto, ampliar conhecimentos na área de nutrição e adubação da planta é importante para agregar informações no que diz respeito ao crescimento inicial das mudas

Cultura Agronômica, Ilha Solteira, v.25, n.4, p.419-430, 2016 
estabelecidas nos diferentes substratos. Este trabalho teve como objetivo avaliar a calagem, o cultivo orgânico e mineral, na fase de formação de mudas de acerola em viveiro, e também observar as correlações fenotípicas, genotípicas e ambientais entre atributos quantitativos da aceroleira.

\section{MATERIAL E MÉTODOS}

O experimento foi desenvolvido no viveiro da Fazenda de Ensino, Pesquisa e Extensão, da Faculdade de Engenharia da UNESP-Campus de Ilha Solteira, localizado no município de Selvíria-MS, Brasil.

No trabalho foi utilizada terra proveniente da camada de 0 a $20 \mathrm{~cm}$ de um Latossolo Vermelho distrófico típico argiloso a moderado que em combinação com outros materiais foi utilizado como substrato para a produção das mudas de acerola.

Os tratamentos utilizados foram a terra em mistura com esterco bovino (EB), superfosfato simples (SFS), calcário (PRNT 80\%) e FTE-BR12 (Zn =9\%, B =1,8\%, Cu $=0,8 \%, \mathrm{Fe}=3,5 \%, \mathrm{Mn}=2 \%$ e $\mathrm{Mo}=0,1 \%$ ), cujas proporções foram: 1 ) testemunha (apenas terra); 2) EB (0,10 L/L de solo); 3) SFS + FTE-BR12 (3,86g + 0,05 g/L de solo); 4) SFS + FTE-BR12 + EB (3,86g + 0,05g + 0,10 L/L de solo); 5) calcário (1,36g/L de solo); 6) calcário + EB (1,36g + 0,10 L/L de solo); 7) calcário + SFS + FTE-BR12 (1,36g + 3,86g + 0,05 g/L de solo); 8) SFS + FTE-BR12 + EB + calcário $(3,86 \mathrm{~g}+0,05 \mathrm{~g}+0,10 \mathrm{~L} / \mathrm{L}+1,36 \mathrm{~g} / \mathrm{L}$ de solo).

As quantidades de adubos acrescentadas ao solo foram calculadas levando-se em consideração a análise de solo (Tabela 1). Como recipientes para os substratos, foram utilizados tubetes de polipropileno, com capacidade volumétrica de $180 \mathrm{~cm}^{3}$.

Tabela 1. Resultado da análise do solo utilizado no experimento.

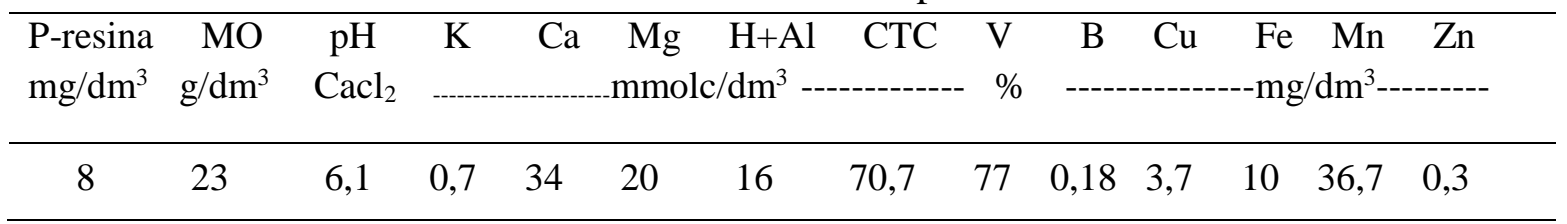

Os clones BRS 236 - Cereja, BRS 237 - Roxinha e BRS 238 - Frutacor, foram semeados em tubetes no mês de julho de 2010, contendo como substrato os tratamentos descritos, os quais foram aleatorizados em bandejas de acordo com o clone. Em cada tubete foram colocadas quatro sementes de acerola, mantidas sob tela de propileno com $50 \%$ de redução da luz. A irrigação foi por microaspersão, realizada sempre que necessária. Quando as plantas apresentavam $10 \mathrm{~cm}$ de altura realizou-se a avaliação quanto a porcentagem de germinação, posteriormente realizou-se o desbaste, deixando apenas a mais vigorosa em cada tubete.

As demais avaliações foram realizadas aos nove meses após a semeadura, quanto ao comprimento da parte aérea, comprimento das raízes, número de folhas, massa da matéria seca da parte aérea e das raízes.

Para avaliação da porcentagem de plantas germinadas em relação a todas sementes, foi 
realizada a contagem das plantas que emergiram e desenvolveram as estruturas essenciais do embrião, demonstrando sua aptidão para produzir uma planta normal sob condições favoráveis de campo. O comprimento da parte aérea das plantas foi obtido, pela distância entre o colo e o ápice da muda, e do sistema radicular, pela distância entre a extremidade da maior raiz e o colo da planta. Para essas mensurações foi utilizada uma régua graduada. $\mathrm{O}$ número de folhas foi obtido pela separação e contagem das folhas em cada tratamento, e a massa seca da parte aérea, e raízes foi obtida após a secagem em estufa de circulação forçada de ar a $65^{\circ} \mathrm{C}$ até atingirem massa constante, então procedeu-se a pesagem em balança analítica.

O teste foi implantado no delineamento em bloco ao acaso, com sementes de três clones, oito tratamentos, com quatro repetições e onze mudas por parcela. Os dados foram analisados mediante o procedimento de análise fatorial simples, AxB do programa Genes (CRUZ, 2006). As médias foram comparadas pelo teste de Tukey, à 5\% de probabilidade. O modelo fatorial simples utilizado foi: Yijk $=\mathrm{m}+\mathrm{Bk}+\mathrm{Gi}+\mathrm{Aj}+\mathrm{GAij}+$ Eijk, em que: $\mathrm{m}=$ média geral; $\mathrm{Bk}$ = efeito de bloco; $\mathrm{Gi}$ = efeito de genótipo; $\mathrm{Aj}$ = efeito de ambiente; GAij = efeito de interação de genótipo com ambiente; Eijk = erro aleatótio associado à interação repetição, genótipo e ambiente.

As estimativas dos coeficientes de correlação genotípica, fenotípica e de ambiente entre os atributos foram obtidas mediante análises de covariâncias, combinando os dados dos seis atributos, em todas as formas possíveis (CRUZ; REGAZZI, 1994).

\section{RESULTADOS E DISCUSSÃO}

Com relação à porcentagem de germinação, verifica-se que esta variou entre 22,72 e $56,81 \%$, porém não houve diferença significativa entre os tratamentos nos clones Cereja e Roxinha (Tabela 2). De modo geral, os valores de germinação do clone Roxinha foram superiores aos demais, demonstrando sua melhor adaptação aos diferentes substratos testados.

Houve diferenças significativas entre os tratamentos quanto a germinação das sementes do clone Frutacor. Os menores valores de germinação foram encontrados nos tratamentos 1 (Testemunha) e 7 (Calcário + SFS + FTE-BR12). Esses resultados foram semelhantes aos obtidos por Ribeiro et al. (2010) que constataram que a germinação de sementes de acerola, é baixa e desuniforme, dificultando a formação de mudas de qualidade. No geral, as sementes apresentaram baixa porcentagem de germinação. Dependendo do grau de maturação do fruto, pode levar meses para germinar, sendo comum a ocorrência de sementes inviáveis, em relação à futura germinação. Isso porque, dos três óvulos existentes, apenas um ou dois se desenvolvem, fato este em decorrência de fatores como a má formação do óvulo, a degeneração do saco embrionário e a falta de fertilização do óvulo, dentre outros, que resultam na baixa germinação (COSTA et al., 2003).

Cultura Agronômica, Ilha Solteira, v.25, n.4, p.419-430, 2016 
Tabela 2. Médias de porcentagem de germinação de sementes das mudas de três clones de acerola em diferentes substratos. Selvíria, MS, 2011.

\begin{tabular}{|c|c|c|c|c|}
\hline \multirow{2}{*}{ Tratamentos } & \multicolumn{3}{|c|}{ Clones } & \multirow{2}{*}{ Médias } \\
\hline & Cereja & Roxinha & Frutacor & \\
\hline $1-$ Testemunha & $24,99 \mathrm{aB}$ & $55,68 \mathrm{aA}$ & $26,13 \mathrm{bB}$ & 30,20 \\
\hline $2-\mathrm{EB}$ & $22,72 \mathrm{aB}$ & $42,04 \mathrm{aA}$ & $36,38 \mathrm{abAB}$ & 33,71 \\
\hline 3 - SFS + FTE-BR12 & $36,36 \mathrm{aB}$ & $56,81 \mathrm{aA}$ & $35,22 \mathrm{abB}$ & 42,79 \\
\hline 4 - SFS + FTE-BR12 + EB & $29,54 \mathrm{aA}$ & $43,18 \mathrm{aA}$ & $40,90 \mathrm{abA}$ & 37,87 \\
\hline 5 - Calcário & $23,86 \mathrm{aB}$ & $43,18 \mathrm{aA}$ & $40,91 \mathrm{abA}$ & 35,98 \\
\hline 6 - Calcário + EB & $24,99 \mathrm{aB}$ & $45,45 \mathrm{aA}$ & $52,27 \mathrm{aA}$ & 40,90 \\
\hline 7 - Calcário + SFS + FTE-BR12 & $24,99 \mathrm{aA}$ & $40,90 \mathrm{aA}$ & $29,54 \mathrm{bA}$ & 31,81 \\
\hline 8 - SFS + FTE-BR $12+$ EB + calc. ${ }^{1}$ & $38,63 \mathrm{aA}$ & $48,86 \mathrm{aA}$ & $32,95 \mathrm{abA}$ & 40,14 \\
\hline Médias & 28,26 & 47,01 & 36,78 & \\
\hline $\mathrm{CV}(\%)$ & & 26,66 & & \\
\hline
\end{tabular}

Médias na coluna seguidas pela mesma letra minúscula e na mesma linha pela letra maiúscula não diferem entre si, a 5\% de probabilidade pelo teste de Tukey. ${ }^{1}$ calc. - calcário.

$\mathrm{Na}$ Tabela 3 pode-se verificar que a maior altura das plantas para o clone Cereja, foi obtida no tratamento 8 (SFS + FTE-BR12 + EB + calcário) com 13,70 cm, e o menor valor obtido no tratamento 7 (Calcário + SFS + FTE-BR12) com 8,24 cm. Os menores resultados foram obtidos nos tratamentos em que não foi adicionado esterco bovino ao solo $(1,5,7)$, excetuando-se o tratamento 3 (SFS + FTE-BR12 + EB), o qual não diferiu daqueles tratamentos que possuíam o adubo orgânico. Tais resultados podem evidenciar que o esterco bovino melhorou as condições físicas do substrato, aumentando a capacidade de retenção de água e aeração. Para os clones Roxinha e Frutacor não ocorreram diferenças significativas entre os tratamentos. Vale acrescentar que substratos que em sua composição contêm bom teor de matéria orgânica e elevada porosidade total apresentam boa capacidade de retenção de água e aeração, produzindo assim mudas mais vigorosas.

Em relação à comparação entre clones por tratamentos, para altura de plantas, verificouse que ocorreram diferenças significativas apenas para o tratamento 8 (SFS + FTE-BR12 + $\mathrm{EB}+$ calcário), onde a maior altura foi obtida para o clone Cereja e a menor no clone Roxinha. Nesse caso pode-se considerar que parte dessa variação seja de origem genética, uma vez que o clone Roxinha apresenta a menor altura geral entre os clones, e no seu processo de melhoramento foi selecionado justamente por apresentar porte baixo. No tratamento 7 (Calcário + SFS + FTE-BR12), o clone Cereja apresentou a menor altura, diferença essa provavelmente, pela menor disponibilidade de nutrientes no substrato, como por exemplo o fósforo, primordial no crescimento de plantas jovens.

Com relação ao comprimento radicular (Tabela 3) verificou-se que variou entre 16,61 e 12,62 cm, entretanto, sem diferença significativa entre os tratamentos e os clones. $\mathrm{O}$ comprimento das raízes não teve interferência dos substratos, concordando com o observado

Cultura Agronômica, Ilha Solteira, v.25, n.4, p.419-430, 2016 
por Bordin et al. (2005), em plantas aceroleira submetidas a tipos de propagação e densidades de solo do substrato.

Tabela 3. Médias de comprimento da parte aérea (CPA) e das raízes (CPR) das mudas de três clones de acerola em diversos substratos. Selvíria, MS, 2011.

\begin{tabular}{|c|c|c|c|c|}
\hline \multirow{2}{*}{$\begin{array}{c}\text { CPA } \\
\text { Tratamentos }\end{array}$} & \multicolumn{3}{|c|}{ Clones } & \multirow{2}{*}{ Médias } \\
\hline & Cereja & Roxinha & Frutacor & \\
\hline 1 - Testemunha & $8,80 \mathrm{bcA}$ & $8,61 \mathrm{aA}$ & $9,10 \mathrm{aA}$ & 8,83 \\
\hline $2-\mathrm{EB}$ & $12,11 \mathrm{abA}$ & $9,75 \mathrm{aA}$ & $11,67 \mathrm{aA}$ & 11,17 \\
\hline 3 - SFS + FTE-BR12 & $11,44 \mathrm{abcA}$ & $9,41 \mathrm{aA}$ & $8,76 \mathrm{aA}$ & 9,87 \\
\hline 4 - SFS + FTE-BR12 + EB & $13,44 \mathrm{aA}$ & $11,26 \mathrm{aA}$ & $11,52 \mathrm{aA}$ & 12,07 \\
\hline 5-Calcário & $8,60 \mathrm{bcB}$ & $8,85 \mathrm{aA}$ & 8,86 aA & 8,77 \\
\hline 6 - Calcário + EB & $13,36 \mathrm{aA}$ & $11,98 \mathrm{aA}$ & $10,71 \mathrm{aA}$ & 12,01 \\
\hline 7 - Calcário + SFS + FTE-BR12 & $8,24 \mathrm{cA}$ & $9,41 \mathrm{aA}$ & $9,40 \mathrm{aA}$ & 9,01 \\
\hline $8-$ SFS + FTE-BR $12+$ EB + calc. ${ }^{1}$ & $13,70 \mathrm{aA}$ & $9,97 \mathrm{aB}$ & $11,65 \mathrm{aAB}$ & 11,77 \\
\hline Médias & 11,21 & 9,90 & 10,20 & \\
\hline $\mathrm{CV}(\%)$ & & 16,10 & & \\
\hline \multirow[t]{2}{*}{$\begin{array}{c}\text { CPR } \\
\text { Tratamentos }\end{array}$} & \multicolumn{3}{|c|}{ Clones } & Médias \\
\hline & Cereja & Roxinha & Frutacor & \\
\hline $1-$ Testemunha & $14,48 \mathrm{aA}$ & $14,11 \mathrm{aA}$ & $14,17 \mathrm{aA}$ & 14,25 \\
\hline $2-\mathrm{EB}$ & $12,94 \mathrm{aA}$ & $14,22 \mathrm{aA}$ & $14,36 \mathrm{aA}$ & 13,84 \\
\hline 3 - SFS + FTE-BR12 & $12,70 \mathrm{aA}$ & $13,68 \mathrm{aA}$ & $14,05 \mathrm{aA}$ & 13,48 \\
\hline 4 - SFS + FTE-BR12 + EB & $12,62 \mathrm{aA}$ & $13,92 \mathrm{aA}$ & $14,14 \mathrm{aA}$ & 13,56 \\
\hline 5 - Calcário & $13,98 \mathrm{aA}$ & $13,81 \mathrm{aA}$ & $13,80 \mathrm{aA}$ & 13,86 \\
\hline 6 - Calcário + EB & $14,25 \mathrm{aA}$ & $14,25 \mathrm{aA}$ & $14,10 \mathrm{aA}$ & 14,20 \\
\hline 7 - Calcário + SFS + FTE-BR12 & $14,14 \mathrm{aA}$ & $13,97 \mathrm{aA}$ & $14,10 \mathrm{aA}$ & 14,07 \\
\hline 8 - SFS + FTE-BR $12+$ EB + calc. ${ }^{1}$ & $16,61 \mathrm{aA}$ & $13,98 \mathrm{aA}$ & $14,13 \mathrm{aA}$ & 14,91 \\
\hline Médias & 13,97 & 13,99 & 14,11 & \\
\hline $\mathrm{CV}(\%)$ & & 6,67 & & \\
\hline
\end{tabular}

Médias na coluna seguidas pela mesma letra minúscula e na mesma linha pela letra maiúscula não diferem entre si, a $5 \%$ de probabilidade pelo teste de Tukey. ${ }^{1}$ calc. - calcário.

Para o número de folhas por planta foram encontradas diferenças significativas entre os clones e os tratamentos, exceto para o clone Frutacor. (Tabela 4).

Analisando-se a Tabela 4, verifica-se que o clone Roxinha, apresentou o maior número de folhas em todos os tratamentos, destacando-se no tratamento 8 (SFS + FTE-BR12 + EB + calcário), e com menor valor no tratamento 5 (apenas calcário). No clone Cereja, o melhor resultado também foi do tratamento 8 (SFS + FTE-BR12 + EB + calcário), e o pior dos tratamentos 1, 2, 5 e 7, todos sem esterco bovino, corroborando com os resultados obtidos para altura das mudas (Tabela 3 ).

Cultura Agronômica, Ilha Solteira, v.25, n.4, p.419-430, 2016 
A presença de mais folhas em mudas de aceroleira proporcionou maior massa seca (média de 3,96 g) de raízes no mesmo clone. Isso porque, as folhas são requisitos essenciais para o enraizamento das estacas (COSTA et al., 2015; SILVA, 1998), tendo demonstrado grande participação no processo de enraizamento, por contribuírem com a taxa fotossintética e incorporação de nutrientes ao tecido vegetal (OLIVEIRA, 2000).

Tabela 4. Médias do número de folhas das mudas de três clones de acerola em diversos substratos. Selvíria, MS, 2011

\begin{tabular}{|c|c|c|c|c|}
\hline \multirow{2}{*}{ Tratamentos } & \multicolumn{3}{|c|}{ Clones } & \multirow{2}{*}{ Médias } \\
\hline & Cereja & Roxinha & Frutacor & \\
\hline $1-$ Testemunha & $25,50 \mathrm{bB}$ & $106,50 \mathrm{abcA}$ & $42,50 \mathrm{aB}$ & 58,50 \\
\hline $2-\mathrm{EB}$ & $29,50 \mathrm{bB}$ & $94,75 \mathrm{bcA}$ & $58,50 \mathrm{aAB}$ & 60,92 \\
\hline 3 - SFS + FTE-BR12 & $70,00 \mathrm{abB}$ & $144,75 \mathrm{abA}$ & $60,00 \mathrm{aB}$ & 91,58 \\
\hline $4-\mathrm{SFS}+\mathrm{FTE}-\mathrm{BR} 12+\mathrm{EB}$ & $67,00 \mathrm{abB}$ & $110,00 \mathrm{abcA}$ & $87,00 \mathrm{aAB}$ & 88,00 \\
\hline 5 - Calcário & $27,75 \mathrm{bB}$ & $83,50 \mathrm{cA}$ & $62,00 \mathrm{aAB}$ & 57,75 \\
\hline 6 - Calcário + EB & $45,50 \mathrm{abB}$ & $100,00 \mathrm{abcA}$ & $92,50 \mathrm{aA}$ & 79,93 \\
\hline 7 - Calcário + SFS + FTE-BR12 & $29,75 \mathrm{bB}$ & $92,75 \mathrm{cA}$ & $48,50 \mathrm{aB}$ & 57,00 \\
\hline 8 - SFS + FTE-BR $12+$ EB + calc. ${ }^{1}$ & $85,50 \mathrm{aB}$ & $147,00 \mathrm{aA}$ & $60,75 \mathrm{aB}$ & 97,75 \\
\hline Médias & 47,56 & 109,90 & 63,97 & \\
\hline $\mathrm{CV}(\%)$ & & 31,64 & & \\
\hline
\end{tabular}

Médias na coluna seguidas pela mesma letra minúscula e na mesma linha pela letra maiúscula não diferem entre si, a $5 \%$ de probabilidade pelo teste de Tukey. ${ }^{1}$ calc. - calcário.

Quanto à matéria seca das raízes (Tabela 5), foram encontradas diferenças significativas em relação aos clones e aos tratamentos com exceção ao clone Roxinha. O maior valor foi obtido no clone Cereja, com 5,83 g referente ao tratamento 8 (SFS + FTE-BR12 + EB + calcário), resultado este provavelmente atribuído ao melhor balanço e disponibilidade de nutrientes. Enquanto que o menor valor foi constatado no clone Frutacor, com 0,83 g, referente ao tratamento 1 (Testemunha), com apenas terra em sua constituição.

Segundo Assis et al. (2012), em trabalho com maracujá doce, houve incremento da matéria seca do sistema radicular, com aumento das doses de matéria orgânica e de nutrientes. Para Antunes et al. (2000), a muda formada com maior quantidade de matéria seca das raízes e parte aérea, reflete uma planta mais preparada para suportar as condições de campo no momento do plantio em local definitivo.

Em relação à matéria seca da parte aérea (Tabela 5), foram encontrados resultados significativos em relação aos clones e aos tratamentos, com exceção ao clone Roxinha.

A maior produção de matéria seca foi do clone Cereja $(4,33 \mathrm{~g})$, referente ao tratamento 8 (SFS + FTE-BR12 + EB + calcário), e a menor no clone Frutacor $(0,38$ g), referente ao tratamento 1 (Testemunha). Esses resultados seguiram o mesmo padrão da massa seca da raiz, os quais podem ser justificados devido à melhor qualidade de substrato na nutrição das mudas no Tratamento 8 , e pela baixa fertilidade do solo no Tratamento 1 .

Cultura Agronômica, Ilha Solteira, v.25, n.4, p.419-430, 2016 
Tabela 5. Médias da matéria seca da raiz (MSR) e matéria seca da parte aérea (MSPA) de três clones de acerola em diversos substratos. Selvíria, MS, 2011.

\begin{tabular}{|c|c|c|c|c|}
\hline \multirow{2}{*}{$\begin{array}{c}\text { MSR } \\
\text { Tratamentos }\end{array}$} & \multicolumn{3}{|c|}{ Clones } & \multirow{2}{*}{ Médias } \\
\hline & Cereja & Roxinha & Frutacor & \\
\hline $1-$ Testemunha & $2,80 \mathrm{bA}$ & $3,40 \mathrm{Aa}$ & $0,83 \mathrm{cB}$ & 2,34 \\
\hline $2-\mathrm{EB}$ & $3,25 \mathrm{bAB}$ & $3,88 \mathrm{aA}$ & $2,38 \mathrm{abcB}$ & 3,17 \\
\hline 3 - SFS + FTE-BR12 & $3,30 \mathrm{bA}$ & $3,85 \mathrm{aA}$ & $1,05 \mathrm{bcB}$ & 2,73 \\
\hline 4 - SFS + FTE-BR12 + EB & $4,23 \mathrm{abA}$ & $4,23 \mathrm{aA}$ & $2,60 \mathrm{abB}$ & 3,69 \\
\hline 5 - Calcário & $3,03 \mathrm{bA}$ & $3,35 \mathrm{aA}$ & $1,65 \mathrm{abcB}$ & 2,68 \\
\hline 6 - Calcário + EB & $3,90 \mathrm{bAB}$ & $4,85 \mathrm{aA}$ & $3,08 \mathrm{aB}$ & 3,94 \\
\hline 7 - Calcário + SFS + FTE-BR12 & $2,63 \mathrm{bB}$ & $4,13 \mathrm{aA}$ & $1,20 \mathrm{bcC}$ & 2,65 \\
\hline 8 - SFS + FTE-BR $12+$ EB + calc. $^{1}$ & $5,83 \mathrm{aA}$ & $3,98 \mathrm{aB}$ & $3,13 \mathrm{aB}$ & 4,31 \\
\hline Médias & 3,62 & 3,96 & 1,99 & \\
\hline $\mathrm{CV}(\%)$ & \multicolumn{3}{|c|}{22,94} & \\
\hline MSPA & \multicolumn{3}{|c|}{ Clones } & \multirow{2}{*}{ Médias } \\
\hline Tratamentos & Cereja & Roxinha & Frutacor & \\
\hline $1-$ Testemunha & $2,48 \mathrm{bcA}$ & $2,68 \mathrm{aA}$ & $0,38 \mathrm{cB}$ & 1,85 \\
\hline $2-\mathrm{EB}$ & $2,65 \mathrm{bcA}$ & $2,88 \mathrm{aA}$ & $0,95 \mathrm{abcB}$ & 2,16 \\
\hline 3 - SFS + FTE-BR12 & $2,98 \mathrm{bcA}$ & $2,75 \mathrm{aA}$ & $0,48 \mathrm{cB}$ & 2,07 \\
\hline 4 - SFS + FTE-BR12 + EB & $3,20 \mathrm{bA}$ & $2,98 \mathrm{aA}$ & $1,25 \mathrm{abcB}$ & 2,48 \\
\hline 5 - Calcário & $2,50 \mathrm{bcA}$ & $2,73 \mathrm{aA}$ & $0,75 \mathrm{bcB}$ & 1,99 \\
\hline 6 - Calcário + EB & $3,00 \mathrm{bcA}$ & $3,38 \mathrm{aA}$ & $1,58 \mathrm{abB}$ & 2,65 \\
\hline 7 - Calcário + SFS + FTE-BR12 & $2,20 \mathrm{cA}$ & $2,93 \mathrm{aA}$ & $0,48 \mathrm{cB}$ & 1,87 \\
\hline 8 - SFS + FTE-BR12 + EB + calc. ${ }^{1}$ & $4,33 \mathrm{aA}$ & $3,08 \mathrm{Ab}$ & $1,73 \mathrm{aC}$ & 3,05 \\
\hline Médias & 2,92 & 2,93 & 0,95 & \\
\hline $\mathrm{CV}(\%)$ & & 19,04 & & \\
\hline
\end{tabular}

Médias na coluna seguidas pela mesma letra minúscula e na mesma linha pela letra maiúscula não diferem entre si, a 5\% de probabilidade pelo teste de Tukey. ${ }^{1}$ calc. - calcário.

Com relação aos clones, o Frutacor apresentou diferenças significativas para todos os tratamentos utilizados, cujos valores de massa de matéria seca da parte aérea foram os menores em todos os tratamentos, quando comparado aos demais clones testados.

As relações existentes entre os atributos são, em geral, avaliadas por meio da estimativa e do sinal dos coeficientes de correlação genotípica, fenotípica e de ambiente. Estudos das associações entre atributos fornecem informações importantes para o melhoramento genético, como a quantificação da porção de correlação fenotípica que é devida às causas genéticas e à mensuração de ganhos indiretos devido à seleção efetuada em atributos correlacionados (VENCOVSKY; BARRIGA, 1992).

Verifica-se que, na maioria dos casos, os pares avaliados apresentaram coeficientes de correlação fenotípica e genotípica com os mesmos sinais e com correlações genotípicas ligeiramente superiores às fenotípicas, sugerindo que para a maior parte dos atributos, a 
influência ambiental foi baixa (Tabela 6). As correlações fenotípicas e genotípicas altas encontradas para porcentagem de germinação e número de folhas, $(0,9865$ e 0,9771, respectivamente para correlações genotípicas e fenotípicas), indicam que a seleção de um desses dois caracteres pode ser feita por meio apenas da seleção daquele de mais fácil mensuração. As correlações fenotípicas e genotípicas da massa seca da parte aérea com a massa seca das raízes apresentaram altos valores positivos, $(0,9913$ e 0,9875, respectivamente) indicando que a maior a massa da parte aérea resulta da maior massa seca de raízes.

Tabela 6. Coeficientes de correlação genotípica (rG), fenotípica (rF) e ambiental (rE) entre seis caracteres avaliados de acerola. UNESP, Ilha Solteira, 2011.

\begin{tabular}{|c|c|c|c|c|c|c|c|}
\hline Caracteres & $\mathrm{R}$ & $\% \mathrm{G}$ & CPA & CR & $\mathrm{NF}$ & PA & PR \\
\hline \multirow{3}{*}{$\% \mathrm{G}$} & $\mathrm{G}$ & 1 & $-1,0474$ & 1 & 0,9865 & 0,515 & 0,2072 \\
\hline & $\mathrm{F}$ & 1 & $-0,939$ & 0,6516 & 0,9771 & 0,552 & 0,2118 \\
\hline & $\mathrm{E}$ & 1 & $-0,1513$ & $-0,2306$ & 0,669 & 0,376 & 0,4252 \\
\hline \multirow{3}{*}{ CPA } & $\mathrm{G}$ & & 1 & $-1,5003$ & $-0,938$ & 0,3172 & 0,1425 \\
\hline & $\mathrm{F}$ & & 1 & $-0,8728$ & $-0,8442$ & 0,2917 & 0,1373 \\
\hline & $\mathrm{E}$ & & 1 & $-0,2391$ & $-0,113$ & 0,2278 & 0,1868 \\
\hline \multirow{3}{*}{ CR } & $\mathrm{G}$ & & & 1 & 0,8347 & $-1,2336$ & $-1,0227$ \\
\hline & $\mathrm{F}$ & & & 1 & 0,4753 & $-0,7214$ & $-0,6033$ \\
\hline & $\mathrm{E}$ & & & 1 & $-0,745$ & $-0,604$ & $-0,1115$ \\
\hline \multirow{3}{*}{$\mathrm{NF}$} & $\mathrm{G}$ & & & & 1 & 0,2261 & 0,4145 \\
\hline & $\mathrm{F}$ & & & & 1 & 0,2264 & 0,415 \\
\hline & $\mathrm{E}$ & & & & 1 & 0,3633 & 0,4437 \\
\hline \multirow{3}{*}{ PA } & $\mathrm{G}$ & & & & & 1 & 0,9913 \\
\hline & $\mathrm{F}$ & & & & & 1 & 0,9875 \\
\hline & $\mathrm{E}$ & & & & & 1 & 0,7254 \\
\hline \multirow{3}{*}{ PR } & $\mathrm{G}$ & & & & & & 1 \\
\hline & $\mathrm{F}$ & & & & & & 1 \\
\hline & $\mathrm{E}$ & & & & & & 1 \\
\hline
\end{tabular}

$\% \mathrm{G}$ - porcentagem de plantas germinadas; $\mathrm{CPA}$ - comprimento da parte aérea; $\mathrm{CR}$ - comprimento da raiz; NF número de folhas; PA - massa seca da parte aérea; PR - massa seca da raiz.

Quando há correlação significativa entre dois atributos, é possível obter ganho em um deles por meio da seleção indireta do outro. Isso é vantajoso, principalmente, quando um atributo de elevado valor econômico possui baixa herdabilidade e, ou, difícil avaliação, quando comparado a outro que está associado a ele. Dessa forma, a seleção é feita no atributo que apresenta alta herdabilidade e/ou fácil mensuração, visando melhorar o outro (NUNES et al., 2008). Dessa maneira, se for realizada uma seleção preliminar nas plantas com maior porcentagem de germinação, sabe-se que elas também terão maior número de folhas. Essa informação seria de grande utilidade para os produtores, uma vez que parâmetros de 
crescimento estão relacionados com a produtividade da cultura (WILHELM; MCMASTER, 1995).

Valores de correlações ambientais negativos e altos foram observados entre porcentagem de germinação e comprimento da parte aérea (correlação genotípica e fenotípica de -1,0474 e -0,939), comprimento da parte aérea e comprimento radicular (correlação genotípica e fenotípica de -1,5003 e -0,872), comprimento da parte aérea e número de folhas (correlação genotípica e fenotípica de -0,938 e -0,8442), comprimento radicular e matéria seca da parte aérea (correlação genotípica e fenotípica de -1,2336 e -0,7214) e entre comprimento radicular e massa seca das raízes (correlação genotípica e fenotípica de -1,0227 e -0,6033). Adicionalmente, vale destacar os sinais negativos de algumas correlações ambientais entre pares de atributos, o que indica que o ambiente altera um em detrimento do outro, como na maioria das correlações do presente trabalho. Ressaltam-se nesse sentido as correlações ambientais negativas para comprimento radicular e número de folhas $(-0,745)$ e comprimento radicular e massa seca da parte aérea $(-0,604)$, demonstrando que o ambiente favoreceu o maior comprimento das raízes, assim, plantas com raízes mais longas produziram menos folhas, e consequentemente, menor massa seca da parte aérea.

As correlações estimadas possibilitaram conhecer as associações entre os atributos, fornecendo importantes informações para o estabelecimento de um plano de produção de mudas de acerola, com possíveis estratégias para uso de substratos e adubações, de modo a visar o bom desenvolvimento inicial das plantas.

\section{CONCLUSÃO}

a) A adição de esterco bovino no substrato propiciou mudas com maior qualidade, especialmente se acompanhada de adubação mineral;

b) O substrato com superfosfato simples (SFS) + FTE-BR12 + esterco bovino + calcário e com SFS + FTE-BR12 + esterco bovino propiciou maior desenvolvimento das mudas de acerola;

c) Houve correlações genotípicas e fenotípicas positivas diretamente proporcionais entre porcentagem de germinação e número de folhas, massa seca da parte aérea e massa seca das raízes das mudas de acerola aos 9 meses após o plantio.

\section{AGRADECIMENTOS}

Agradeço à CAPES (Coordenação de Aperfeiçoamento de Pessoal de Nível Superior) pela concessão da bolsa de estudo de doutorado.

Cultura Agronômica, Ilha Solteira, v.25, n.4, p.419-430, 2016 


\section{REFERÊNCIAS BIBLIOGRÁFICAS}

ALVES, R. E. Características das frutas para exportação. In: GORGATTI, N. A. Acerola para exportação: procedimentos de colheita e pós-colheita. Brasília: Embrapa-SPI, 1995. p. 9-21. (Série Frupex, 21).

ANTUNES, L. E. C.; CHALFUN, N. N. J.; REGINA, M. A. Propagação de cultivares de amoreira preta (Rubus spp) através de estacas lenhosas. Revista Brasileira de Fruticultura, Cruz das Almas, v. 22, n. 2, p.195-199, 2000.

ASSIS, J. T. DE; CORRÊA, L. S.; FERNANDES. F. M. Adubação orgânica, mineral e calagem no crescimento de mudas de maracujá doce. Revista Cultura Agronômica, Ilha Solteira, v. 21, n. 2, p.43-54, 2012.

BORDIN, I; NEVES, C. S. V. J.; AZEVEDO, M. C. B. A.; VIDAL, L. H. I. Desenvolvimento de mudas de aceroleira propagadas por estacas e sementes em solo compactado. Ciência Rural, Santa Maria, v. 35, n. 3, p.530-536, 2005.

CARDONA, W. A; BENAVIDES, M. M. B; MONTOYA, W. C. Efecto de fertilizantes químicos y orgánicos sobre la agregación de un suelo cultivado con Musa acuminata AA. Acta Agronómica, Colômbia, v. 65, n. 2, p.144-148, 2016.

COSTA, E. M; LOSS. A; PEREIRA; H. P. N; ALMEIDA; J. F. Enraizaimento de estacas de Bougainvillea spectabilis Willd com o uso de ácido indolbutírico. Acta Agronómica, Colômbia, v. 64, n. 3, p.221-226, 2015.

COSTA, L. C.; PAVANI, M. C. M. D.; MORO, F. V.; PERECIN, D. Viabilidade de sementes de acerola (Malpighia emerginata D.C.): avaliação da vitalidade dos tecidos. Revista Brasileira de Fruticultura, Cruz das Almas, v. 25, n.3, p.532- 534, 2003.

CRISÓSTOMO, L. A.; NAUMOV, A. Adubando para alta produtividade e qualidade: fruteiras tropicais do Brasil. Fortaleza: Embrapa Agroindústria Tropical, 2009. 238 p.

CRUZ, C. D. Programa Genes: Aplicativo Computacional em Genética e Estatística. Viçosa: UFV, 2006. 442 p.

CRUZ, C. D.; REGAZZI, A. J. Modelos biométricos aplicados ao melhoramento genético. Viçosa: UFV, Imprensa Universitária, 1994. 390 p.

FARIAS; W.C.; OLIVEIRA, L. L. P.; OLIVEIRA, T. A.; DANTAS, L. L. G. R; SILVA, T.A.G. Caracterização física de substratos alternativos para produção de mudas. Agropecuária Científica no Semi-Árido, Campina Grande, v. 8, n. 3, p.1-5, 2012.

LIMA, R. L. S; SIQUEIRA, D. L.; WEBER, O. B.; BUENO, D. M.; CECON, P. R. Enraizamento de estacas caulinares de acerola em função da composição do substrato. Semina: Ciências Agrárias, Londrina, v. 26, n. 1, p.27-32, 2005.

Cultura Agronômica, Ilha Solteira, v.25, n.4, p.419-430, 2016 
NEGREIROS, J. R. S.; ÁLVARES, V. S.; BRAGA, L. R.; BRUCKNER, C. H. Diferentes substratos na formação de mudas de maracujazeiro-amarelo. Revista Ceres, Viçosa, v. 51, n. 29, p.243-345, 2004.

NUNES, G. H. S.; BARROS, A. K. A.; QUEIROZ, M. A.; SILVA, R. A.; LIMA, L. L. Correlações entre características de meloeiro. Caatinga, Mossoró, v. 21, n. 1, p.107-112, 2008.

OLIVEIRA, J. A. Efeito dos substratos artificiais no enraizamento e no desenvolvimento de maracujazeiro-azedo e doce por estaquia, 2000. 71 f. Dissertação (Mestrado em agronomia - Sistema de Produção) - Universidade de Brasília, Brasília, 2000.

PEDÓ, T.; TIAGO Z. A.; LEANDRO, C. O.; LEONARDO, N.; TÂNIA B. G. A. MORSELLI, C. R. M. Productivity and physico-chemical characterization of peppers fruits under different sources and doses of organic manure. Revista de la Facultad de Agronomía, La Plata, v. 113, n. 2, p.134-139, 2014.

RIBEIRO, V. V.; JESUS, B. M.; BRITO, N. M.; NEVES, C. M. L. Viabilidade de sementes de acerola influenciadas pelo substrato e períodos de colheita. BIOFAR: Revista de Biologia e Farmácia, João Pessoa, v. 4, n. 2, p.127-131, 2010.

SILVA, M. N. Enraizamento de estacas de seis espécies nativas de mata galeria. 1998. 112 f. Dissertação (Mestrado em agronomia - Sistema de Produção) - Universidade de Brasília , Brasília1998.

VENCOVSKY, R.; BARRIGA, P. Genética biométrica no fitomelhoramento. Ribeirão Preto: Sociedade Brasileira de Genética, 1992. 486 p.

WILHELM, W. W.; MCMASTER, G. S. Importance of the phyllochron in studyng development and growth in grasses. Crop Science, Madison, v. 35, n. 1, p.1-3, 1995. 